\title{
An Inclusive Review on Load Frequency Control in Deregulated Market
}

\author{
Shital M. Pujara ${ }^{1}$ and Chetan D. Kotwal ${ }^{2}$ \\ ${ }^{1}$ EE. Dept, Charusat University, Gujarat, India \\ ${ }^{2}$ EE. Dept., SVIT, Vasad, Gujarat, India \\ smpujara4@yahoo.co.in, chetan.kotwal@gmail.com
}

\begin{abstract}
Load frequency control is one of the most important ancillary services brought in after deregulation of electricity market, which must be procured by the system operator from the market participants by some regulatory mechanism or by using market-based approaches. This paper presents an overview of load frequency control service prevailing in India and other developed countries after deregulation. Brief review on various control strategies proposed by researchers to design LFC controller to regulate the frequency in deregulated market has been covered. Finally, price based frequency linked load frequency control scheme has been discussed.
\end{abstract}

Keywords: Ancillary Service, Load Frequency Control, Deregulated Market, Unscheduled Interchange.

\section{Introduction}

In a deregulated environment, Load Frequency Control (LFC) as an ancillary service acquires a principal role to maintain the complex electric system reliability at an adequate level. The, stabilization of frequency oscillations in an interconnected power system becomes challenging when implemented in competitive environment. The frequency control ancillary service will be a technical requirement for meeting with various power transactions at an acceptable system frequency known as Normal Operating Band (NOB) of frequency with three different level vis. primary, secondary and tertiary control. The primary frequency regulation service, fixes the imbalances continuously and adjusts the active power generation of generating units and consumption of controllable loads to check the deviation in frequency and responds to frequency changes within few seconds. This service can be provided either on a mandatory basis according to the grid code or on bilateral contract basis or through some market based approach. Secondary Frequency Control Service is a centralized automatic or manual control approach (in country like India), which adjusts the active power production of the generating units to restore the frequency at their target values. This control responds to signals received from the system operator (SO) within 5 to 10 minutes. Primary control limits and stops frequency excursions while as secondary control brings the frequency back to its target values. This control responds to signals from the SO within 5 to 10 minutes. Primary control limits and stops frequency excursions while as secondary control brings the frequency back to its target value. Tertiary frequency control service is used to bring manual changes in commitment of generating units and used to restore the primary and secondary frequency control reserves, to manage congestions in the transmission network, and to bring the frequency and the interchanges back to their target value when the secondary control is unable to perform this last task. Its response is within the range of 10 to 30 minutes $[1,2,3]$. The objective of this paper is to present various techniques for the provision of frequency control as an ancillary service adopted around the world by depending on the competitive electricity market. Also, this article will give concise information and ready references of different control strategies implemented for load frequency control with latest research methodology.

The paper is organized as follows. Section II discusses the frequency regulation service in the chosen regions of world, particularly the ones where this service has been recognized and

Received: August $31^{\text {st }}, 2014$. Accepted: September $17^{\text {th }}, 2016$ 
implemented successfully. Section III discusses the frequency control service adopted in India with its operational procedure. Section IV, analyzes about a variety of load frequency control mechanisms after electricity deregulation. Frequency linked real time pricing scheme proposed for deregulated electricity market is discussed in Section V. Finally section VI presents the conclusions of the study.

\section{Frequency Control Service: International Context}

This section covers short-lived history of the frequency control service adopted in country like Australia, Spain, California, New York, Argentina U.K. and Nordic Countries.

\section{A. New York, USA}

In the New York control area, New York ISO (NYISO) offers frequency response ancillary services by committing on-line generators, predominately through the use of AGC, to follow moment-to-moment changes in load. Regulation service is bid into the market by individual units that have AGC capability and wish to participate in the regulation market. Bid information includes regulation response rate $(\mathrm{MW} / \mathrm{min})$ and regulation availability rate (\$/MW) [1].

\section{B. Argentina}

In Argentina, primary frequency regulation is a mandatory service for all the system generators of the dispatch area. Response time of up to 30 seconds for thermal generators and up to 60 seconds for hydraulic generators, with the capability to maintain the service for minutes is required. If a generator is not able to provide the service that has already been committed, it must arrange another generation unit to replace. Secondary frequency regulation is a service under a voluntary provision. Regulation does not specify a minimal time of response, but response period has to be in the range of 10 to 15 minutes. [4].

\section{Spain}

In Spain primary frequency regulation is a mandatory and free service. The service mandates an amount of energy equal to $1.5 \%$ of the nominal power. A response period of 15 seconds is required when frequency deviations are lower than $100 \mathrm{mHz}$, and linearly between 15 and 30 seconds for deviations between 100 and $200 \mathrm{mHz}$. Secondary frequency regulation in Spain can be offered by generators authorized by the system operator. The needed amounts are calculated using Area Control Error (ACE) and it requires a time response of 10 minutes [1, 4].

\section{D. $U K$}

In UK, National Grid Company (NGC) works for frequency control standards to be maintained. The supply of primary frequency regulation is mandatory in UK for all the generators with an installed capacity over $50 \mathrm{MW}$. Generators are set for a drop of 3 to $5 \%$, with a frequency dead band smaller than $\pm 15 \mathrm{mHz}$. Large consumers can provide primary frequency regulation through load shedding, where a response period of 10 seconds and a duration period of 20 seconds are required. The service of secondary frequency regulation is considered as a commercial service and not a mandatory provision. Generators provide it by using AGC and or load shedding. For this service, a response time of 30 seconds and a duration period of 30 minutes are required $[1,5]$.

\section{E. Nordic Countries}

The electrical system of the Nordic countries incorporates the electrical systems of Denmark, Finland, Iceland, Norway and Sweden. In these countries primary frequency regulation service is obligatory and must be provided within 30 seconds after being requested by the system operator. The required quantity is locally calculated in every country. All generating units are required to keep a drop between 2 to $5 \%$. The service of secondary 
frequency regulation is provided in the case of a contingency. For this service, a response time of 15 minutes and a minimal provision period of 4 hours are required $[4,5]$.

\section{F. California, USA}

The process of deregulation in California began in 1992. California Independent System Operator (CAISO) was created to manage the transmission grids and to assure free access to all the market participants. After the year 2001 due to the electric and also financial crisis CAISO redesigned the electric energy market of California introducing the concept of available capacity, whose main objective was to allow the ISO to verify, in advance, the availability of enough capacity to cover both the system load and reserve requirements. In California primary frequency regulation and secondary frequency regulation are not mandatory services. For primary frequency regulation an instantaneous response is required. The required quantity of the service is calculated through area control error as percentage of the total predicted demand for the system, and this value changes according to the time schedule between 5 and $12 \%$ of the load. There exists up and down service regulation. The main cost associated with this service is the capacity cost $[1,4,5]$.

\section{G. Australia}

In Australia, the deregulation of the electricity supply industry began in 1998 and the National Electricity Market Management Company Limited (NEMMCO) is the system operator and the ancillary services market administrator. The system operator can request additional amount of primary frequency regulation, up or down. A response period from 6 to 60 seconds is required and the service should be supplied during 90 seconds. The detail of secondary frequency regulation in Australia as follows:

- Automatic generation control: Is required from a generator within five minutes of the ISO request.

- Governor control: Is based on the generator's governor droop characteristic and aids in frequency control, acting in a 1 second to 1 minute time frame.

- Rapid generator unit loading: It requires from generators not in operation and to synchronize with the system within a five minutes of timeframe.

- Load shedding: It requires curtailment of load following extreme frequency variations. The loads are expected to automatically respond and disconnect within a one-minute time frame $[1,4,5]$.

\section{Frequency Control Service: Indian Context}

In country like India, frequency regulation service is mainly provided by generating units through Free Governor Mode of Operation (FGMO) and with frequency linked self-dispatch regulatory method known as Unscheduled Interchange (UI) mechanism, along with certain guidelines prescribed by Central Electricity Regulatory Commission (CERC) [6]. The other regulatory approach which is also being practiced is Frequency Support Ancillary Service (FSAS).

\section{A. UI Mechanism}

Frequency regulation service by UI mechanism has been provided through a spot market which determines the price by using an incentive/penalty based approach. UI price varies inversely with frequency. For the year 2014; UI price has been set between $49.69 \mathrm{~Hz}$. to 50.05 $\mathrm{Hz}$ (Figure.1) [9]. Normally the maximum price cap is set by CERC to accommodate the highest price generation in the system. 


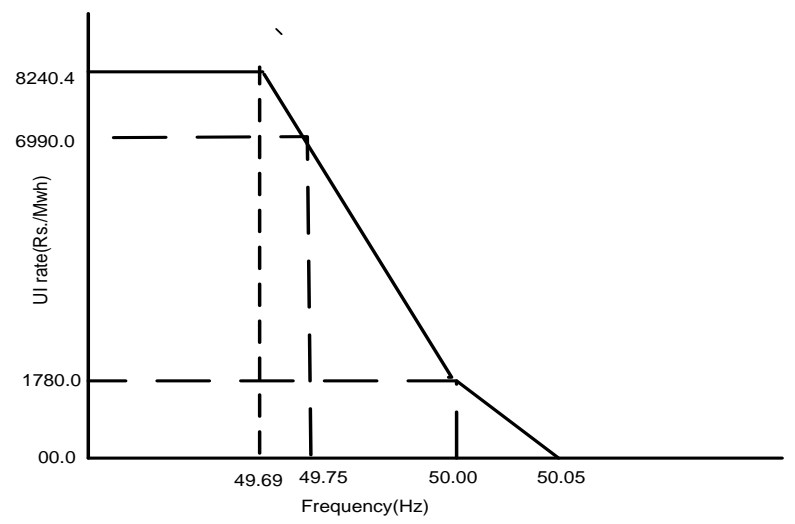

Figure 1. UI rate (CERC, 2014) [9]

\section{B. Frequency Linked Dispatch Guidelines}

CERC issues the frequency linked dispatch guidelines, to avoid deep frequency deviation and for smooth functioning of grid such as:

- For each generating unit an overall droop characteristic is within the range of 3 to $6 \%$ and shall have their governors must be in operation at all times..

- Any generator can generate up to $105 \%$ of the declared capacity in any time block of 15 minutes and averaging up to $101 \%$ of the average declared capacity over a day shall not be interpreted as gaming, and the generator shall be entitled to UI charges for such excess generation above the scheduled generation.

- Variation in grid frequency can be minimized by putting all the generating stations on Free Governor Mode of Operation (FGMO) [7].

- All State Electricity Boards (SEBs), distribution licensees or State Transmission Utility (STU) shall provide automatic under-frequency relays for load shedding in their respective systems to arrest frequency [10].

- The secondary control is operated manually by the operator depending upon the actual frequency and the threshold or breakeven frequency of the generator. The frequency at which the incremental cost of generator becomes equal to the UI rate is known as the threshold or breakeven frequency. If the actual frequency is lower than the threshold frequency, then the generator changes it's setting manually to supply more energy and vice versa up to the limit prescribed by CERC $[7,10]$.

Though, the FGMO and UI mechanism, as described previously, look simple have some shortcomings. The first and foremost technical shortcoming during operation under FGMO is the huge wear and tear losses to arrest transient swings in grid frequency. Further details of it can be found Ref. [11, 12, 13].

\section{FSAS Dispatch Guidelines}

Main objective of Frequency Support Ancillary Service (FSAS) is to stabilize the grid frequency by maximizing unutilized generation and minimizing load shedding, such as harnessing captive power generation from industrial user and also by integrating renewable energy into grid under certain conditions for ensuring grid safety and security. FSAS would be offered through competitive bids by a generating station or any other authorized entity on behalf of the generating station.

Following are the dispatch guide lines [14]:

- If the frequency remains $0.05 \mathrm{~Hz}$ below the lower operating frequency range as specified in the Indian Electricity Grid Code (IEGC) for two consecutive time-blocks, the nodal agency 
gives orders to the FSAS provider to dispatch in the third time block for dispatching generation from the fifth time block.

- During real time congestion in the network, the merit order dispatch of FSAS bids to be discounted. The prescribed limit of the Available Transfer Capability (ATC) across the control area would also be followed while dispatching the bids.

- As long as frequency remains at its nominal value for two consecutive time blocks, after implementation of the FSAS, the nodal agency will issue the notice for withdrawal of FSAS.

- If seller fails to provide the committed generation in real-time then he has to pay 1.5 times the bid price or the applicable UI rate whichever is higher.

\section{Load Frequency Control Strategies}

The real world power system contains different kinds of uncertainties and disturbances, and deregulation has significantly increased the severity of this problem. Under this condition, the classical controller is certainly not suitable for the LFC problem. Plenty of work based on optimal, robust and combined intelligent approach has been carried out to modify conventional LFC to take into account the bilateral contract in competitive market and hence to improve the dynamical transient response of system under deregulated environment. An elaborative discussion about LFC issues before and after deregulation has been reported in [16]. Authors of Ref. [17 -19], have discussed some of the other general issues for solution of LFC problem for power system after deregulation.

Following snippet, discusses about various control strategies used in deregulated power system scenario.

In 1996 authors in Ref. [20], proposed two basic structures 'charged' and 'bilateral' for frequency regulation service in deregulated electricity market scenario and then after most of the research was carried out on LFC in deregulated environment, found to be based on these two basic schemes.

In 'charged' load frequency control scheme the SO must procure real power from Generating Companies (GENCOs) and resale it to Distribution Companies ( DISCOs), on a near to real-time basis. The SO in this scheme seeks to minimize the cost of purchase of regulation energy by employing some form of bidding and auction mechanism. For this scheme, calculation of Area Control Error (ACE) is given by Eq. 1 .

$$
\mathrm{ACE}=\mathrm{NI}_{\text {sked }}-\mathrm{NI}_{\text {act }}-* 10 * \mathrm{~B}\left(\mathrm{f}_{\text {sked }}-\mathrm{f}_{\text {act }}\right)
$$

Where,

$\mathrm{NI}_{\text {sked }}=\sum$ Genco sales $-\sum$ Disco purchases, $\mathrm{NI}_{\mathrm{act}}=$ net interchange, $\mathrm{B}=$ bias in (MW/0.1 Hz, negative value)

$\mathrm{f}=$ frequency in $\mathrm{Hz}$

In a 'Bilateral' LFC structure, the $\mathrm{SO}$ is relieved from the burden of responsibility and has no obligation to provide LFC. Discos must purchase LFC from one or more Gencos. This control is highly decentralized and the control area concept in this scheme is virtual one.

Further bilateral based deregulated market structure and its operating mechanism was presented in Ref. [21, 22] using the concept of participation factors. Author of [23] proposed a concept of a DISCO Participation Matrix (DPM), based on the idea presented by authors in [22]. DPM has been formulated on the basis of superimposing the information flow of the contracts on the traditional LFC system. This concept helps in better visualization and implementation of the various contracts under deregulated environment.

In Ref. [24, 25], authors have focused on LFC by load following concept. They have demonstrated a competitive way to provide this service through bilateral contracts between supplier and customer. For the proposed model, Generation Control Error (GCE) is given by Eq. 2. This can be simulated as Area Control Error (ACE) in conventional LFC.

$$
\mathrm{GCE}=\Delta \mathrm{P}_{\mathrm{gi}}-\Delta \mathrm{P}_{\mathrm{G}}
$$


Where, $\Delta \mathrm{P}_{\mathrm{gi}}=$ demand signal received by generating unit, $\Delta \mathrm{PG}=$ change in generation

another speed droop feedback loop is provided into local control on generator, then again GCE can be defined as in Eq. 3.

$\mathrm{GCE}=-\beta \Delta \omega+\Delta \mathrm{P}_{\mathrm{gi}}-\Delta \mathrm{P}_{\mathrm{G}}$

Where, $\beta=\frac{1}{R}, \Delta \mathrm{P}_{\mathrm{gi}}=\sum \Delta \mathrm{P}_{\mathrm{li}}$

$\Delta \mathrm{P}_{\text {li }}=$ demand signal from each customer

Some of the merits of bilateral contracts are easy allocation of payment and increased competition in ancillary market. It avoids short fall in load following and lessening burden to SO by imparting the liability directly to the customer and supplier.

Later, in [26], authors proposed the framework for Load Following Service (LFS), which receives the power signal of network unbalance, known as Load Following Error (LFE), will excite a reset controller that varies the generator output until power imbalances vanish. Those schemes are Self-providing LFS control scheme and Pool-providing LFS control scheme. Further, same concept was discussed using local controller theory by authors in Ref. [27].

A centralized controller is often considered to be difficult to implement in large-size systems. The advantage of a decentralized controller is to reduce complexity and, therefore, make its implementation more practical in deregulated electricity scenario. Looking at this advantage, different approaches have been put forward by several authors [28-33], implementing such decentralized controller for deregulated market.

To improve the performance of decentralized controller, authors in [28, 29], have projected schemes based on the optimal control theory and based on the load disturbance accommodation theory respectively. Authors in [30] have proposed decentralized Eigen structure based control incorporating various types of transactions taking place in competitive electricity market. Later, in [31], a Two Degree of Freedom (TDF) Internal Model Control (IMC) method was used to tune decentralized PID type load frequency controller in deregulated structure with tieline power flows disconnected.

A decentralized Model Predictive Controller (MPC) proposed in [32], is capable of frequency regulation in its nominal quantity under harsh conditions such as loss of power generation or loss of controllers in some control areas. The MPC controller uses feed forward control strategy in each area of a multi area power system with different scenarios.

A novel decentralized robust Multi input-Multi-Output-proportional-Integral-Differential (MIMO-PID) load frequency controller based on Iterative Linear Matrix Inequality (ILMI) algorithm for two-area reheat thermal power system in deregulated environment has been presented in [33]. To improve its robustness $\mathrm{H}_{\infty}$-norm of the system transfer function is used. Authors in [34-40], have formulated the LFC in a deregulated electricity environment as a multi objective problem and solved by the $\mathrm{H}_{2}$ control and mixed $\mathrm{H}_{2} / \mathrm{H}_{\infty}$ control approach. This model creates a high order system of equations.

To achieve decentralization, in each control area, the areas are treated as a set of new disturbance signals. The proposed control strategy in [34-36], is formulated as general Linear Matrix Inequalities (LMIs) effects of contracted signals and interfaces between control optimization problems. Moreover, authors in [37- 39], have demonstrated that when the frequency response based diagonal dominance cannot be achieved, the $\mathrm{H}_{2}$-norm can be applied to design the decentralized LFC to achieve the desired system dynamic performance, respectively, in such a way that the stability of the overall system with the decentralized controllers is guaranteed. The robust decentralized LFC controller based on structured singular value ( $\mu$-synthesis) was developed with taking into account the uncertainties in deregulated environment[40]. Further multi area robust decentralized LFC design in a restructured power system using quantitative feedback theory has been reported in [41]. 
The increased degree of model order, complex organizational structure leads the prevention of direct application of the standard robust control methodologies in power system.

Different types of controllers are used to maintain the power system in a normal state of operation such as Proportional and Integral (PI), Proportional Integral and Derivative (PID), and optimal controllers. Among other controllers, the fuzzy-based controller is also very efficient in system frequency regulation. In [42-49], authors discussed about intelligent algorithm using fuzzy concept in designing LFC in deregulated environment. Some authors have also suggested a fuzzy controller to provide ancillary services through price-based and bilateral contract mechanisms in a competitive market structure [42, 46]. A Multi Stage Fuzzy (MSF) PID controller with a fuzzy switch has been proposed to solve the AGCs problem in a deregulated power system using the generalized LFC dynamic model. The proposed method requires fewer sources for the operator, and its role in the system response is more apparent $[43,44]$. In a fuzzy control system, optimization of membership function is a computationally expensive problem. So, to reduce fuzzy system effort and to save the cost, a GA based MSF PID controller has been investigated by authors in [45]. A fuzzy based automatic generation controller with a Flexible AC Transmission System (FACTS) device was proposed for frequency control in an open access market scenario. Phase angle control of Thyristor Controlled Phase Shifter (TCPS) was used to stabilize the system frequency and tie-line power oscillations along with fuzzy controller in [47].

Two area hydro-thermal based AGC system, using Polar fuzzy controller has been presented in [48]. This scheme argued to restore the frequency and tie line power to its nominal value with minimum computational efforts considering all system nonlinearities.

In deregulated markets, LFC becomes even more challenging when wind generators are integrated into the system. The overall inertia of the system reduces, as the wind unit does not provide inertia and isolates from the grid during disturbances. The Doubly Fed Induction Generator (DFIGUREs) integrated into the system provides inertial support to the system through modified inertial control scheme, and arrests the initial fall in frequency after disturbance. In [49], authors have carried out the analysis of load frequency control of a deregulated two area hydro-thermal power system using fuzzy logic controller, with doubly fed induction generators integrated into both the control areas.

The human ability to control complex plants has encouraged many researchers to model control based on human neural network systems. The motivation for using a robust control strategy for training a neural network based controller was to take large modeling uncertainties into account, cover physical constraints on control action and minimize the effects of area load disturbances. The applications of Artificial Neural Networks (ANNs) for solution of the LFC problem in competitive environment with different approaches have been reported in Ref. [5055]. The developed effective approaches combined the advantage of the neural networks and robust control technique and led to a flexible controller to provide robust performance. Artificial Intelligent (AI) based methods efficiently managed the non-linearity and mathematical complexity of the system, modeling uncertainties and area load disturbances under different operating conditions. In [56-61], authors have further discussed about improvement in the transient performance of decentralized control using optimized gain controller based on evolutionary algorithm such as Genetic Algorithm (GA), Particle Swarm Optimization (PSO), Bacterial Forging (BF), and Interactive Artificial Bee Colony (IABC). GA is the most popular search algorithm based on the mechanism of natural selection and has been widely used to solve nonlinear LFC problems.

GA application to LFC in competitive market has been reported in Ref. [57-61]. Particle Swarm Optimization is a heuristic based optimization algorithm based on theory of swarm intelligence. Control strategies based on this theory were presented by authors in [56, 57, and 61]. A comparative study of different evolutionary techniques like Modified Chaotic Ant Swarm Optimization (MCASO), Real Coded GA (RGA), conventional PSO, binary coded GA have been demonstrated using four-area multi unit system by authors in [61]. The BF and IABC are also another heuristic based optimization algorithms which recently have 
received great deal of attention due to strong capabilities in solving complex real world optimization problems. Multi area deregulated scheme presented in [62,63] were based on these optimized algorithms have shown superiority to fast suppress the oscillations in deregulated power system. Although, the efforts based on various intelligent approach; difficulties associated with classical methods have been reduced, but the resultant models are still huge enough to be applied in practice. The energy storage devices share the sudden changes in power requirement in the load. Thus, in a power system, the instantaneous mismatch between supply and demand of real power for sudden load changes can be reduced by the addition of active power sources with fast response such as Battery Energy Storage (BES), Super Conducting Magnetic Energy Storage (SMES) etc. Authors in Ref. [64, 65], have investigated LFC performance improvement of unbundled power systems including a SMES unit. In Ref. [66], dynamic participation of the DFIGURE in restructured electricity market to arrest frequency fall is analyzed in coordination with TCPS and SMES. Further, in $[67,68]$ a comparative transient performance of AGC in three-area mixed generation deregulated power system, based on Bacterial Foraging (BF) optimization technique with the presence of energy storage devices like SMES and CES have been analyzed.

In Ref. [69], authors have proposed a thought, based on use of a FACTS device, controlled by a decentralized control law to damp the transient frequency deviation.

High Voltage Direct Current (HVDC) transmission has emerged on a power transmission scenario, due to its numerous technical and economic advantages, for a large chunk of power transfer over large distances. An analysis of dynamic response of conventional tie line and tie line in parallel with HVDC link in three area thermal and hydro -thermal deregulated scheme was prepared by authors in [70,71]. In each case the AC tie-line parallel with HVDC link has shown improved performance. To read further on frequency control strategies in deregulated environment, one can refers survey articles [72, 73].

\section{Price Based Frequency Linked Control Strategies}

Real time pricing of system dynamics is contemplated for regulated utility, where generation and load have the option to automatically monitor a time varying price and to respond as per criterion pre - set by the user. This concept can also be applied to deregulated environment and it was presented in [74]. This paper discussed about how the real time price is determined through a proportional plus integral feedback control in reference to the law of frequency deviations. Key features of this pricing scheme are:

- The independent power plants can themselves monitor the frequency deviations and thus no real time signal needs to be sent by the center electric utility.

- The plants operate to maximize profits, and the loads operate to maximize a satisfaction index.

Only drawback of this scheme is that, no transparent mechanism is used by which suppliers (Gencos) and beneficiaries (loads) can sense real time price through frequency deviation independently.

Later, in [75], authors discussed about the pricing scheme which gives the importing area a signal in terms of increased price for any increment in power drawn apart from its scheduled value. The increase in price is viewed as a penalty which discourages utility to deviate from scheduled power flow and hence ensures the discipline of grid frequency. In Ref. [76], concept of primary and secondary regulation bids from generators and secondary regulation bids from customers were discussed. According to this scheme, price signal acts as a deterrent for over drawl and importing area has to pay for that, depending on how the system operator restores the system frequency. For primary regulation service offered from generators use the relation given in Eq. 4 to increase or decrease their generation.

$$
\Delta \mathrm{P}_{\mathrm{gi}}=\eta_{\text {area }} * \gamma_{\mathrm{i}} * \Delta \mathrm{f}_{\text {area }}
$$

Where, $\eta_{\text {area }}=$ price for generator for per unit of frequency excursion in $\$ / \mathrm{MWh}-\mathrm{Hz}$. $\gamma_{\mathrm{i}}=$ primary regulation bid from generator in p.u $\mathrm{MW} / \mathrm{\$} / \mathrm{MWh}$. 
The real time price signal for secondary frequency regulation is given by Eq.5.

$\Delta \rho(\mathrm{t})=-\int \Delta \mathrm{ACE}_{\mathrm{A}}(\mathrm{t}) \mathrm{dt}$ in $\$ / \mathrm{MWh}$

For secondary regulation service offered by generators, follows below given relation to increase or decrease their generation as in Eq.6.

$$
\Delta \mathrm{P}_{\mathrm{gi}}=\mu_{\mathrm{gi}} * \Delta \rho
$$

Where, $\mu_{\mathrm{gi}}=$ the price sensitivity of generation

Also, a concept based on frequency linked bidding structure, termed as automatic balancing service was presented in [77]. According to this framework the balance provider automatically respond to the frequency linked price signals sent out by the ISO, based on their bid offers, when there is a frequency excursion in the system. Later, in Ref. [78], authors have proposed a scheme for primary and secondary frequency regulation service, based on the concept of elasticity of offer price and elasticity of offer quantity. This structure helps the providers to respond to the system requirements based on the market price variation in real time. For electricity auction, optimization models have been proposed. The selected service providers in each area receive a uniform market price and regulation services activated by frequency deviation linked price signals.

In the literature [79-84], authors have discussed about frequency linked pricing signal, exclusively suitable for Indian electricity market scenario. Ref. [79], has presented two different schemes for real time frequency linked pricing signal. First scheme is about frequency linked bidding structure for the frequency regulation service market based on methodology explained in [77]. Second scheme uses unscheduled interchange rate linked frequency signal to re- dispatch beneficiary in real time their drawl to improve grid frequency and to earn profit by purchasing central sector power when available at cheaper rate.

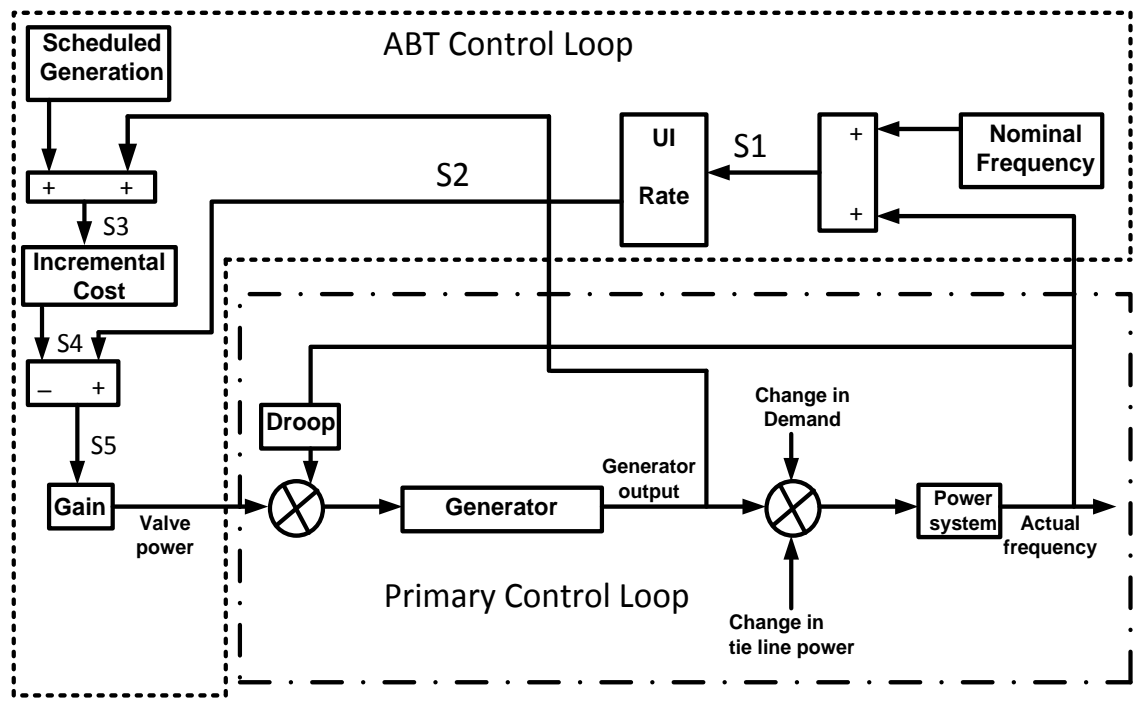

Figure 2. Provision of frequency regulation service by a generator (ABT based frequency control Loop) [80]

In Ref. [80], authors proposed a mathematical framework for provision of frequency regulation service by a generator through two loops derived as shown in (Figure.2). First control loop is a conventional primary control loop and other is a secondary control loop, which operates automatically following UI signal available in real time whenever there is a requirement of more generation that cannot be met through FGMO operation. In this scheme 
feedback signal for controller is the difference of incremental cost of generator responding to load change and UI price at the same instant.

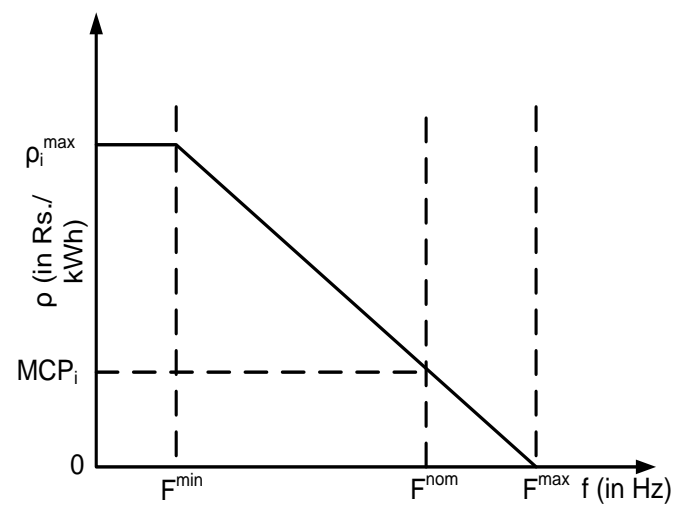

Figure 3. Real time price vs. frequency [81]

In Ref. [81], author proposed the frame work for real time market by an inverse real time price vs. frequency curve. In a day ahead market hourly bids are taken from supplier and load serving entities to discover Market Clearing Price (MCP), point where supply and demand curve meet and represents equilibrium. MCP should be the price of scheduled power at nominal frequency. Taking MCP as a reference, Frequency Linked Unscheduled Interchange Curve (FLUIC) has been derived as shown in Figure.3. The FLUIC price $\rho$ at any frequency can be calculated by Eq.7.

$$
\rho=\mathrm{MCP}_{\mathrm{i}} * \frac{\mathrm{F}^{\mathrm{max}}-\mathrm{f}}{\mathrm{Fmax}_{-} \mathrm{F}^{\text {nom }}}
$$

Since MCP is different at each hour, the curve will be shifting every hour.

In [82], author developed a model based on dynamic UI curve (on hourly basis) rather than static UI curve, which shifts the reference price at nominal frequency simultaneously with the hourly spot market price. Key feature of this model is that the arbitrage opportunity between spot market and real time market can be reduced.

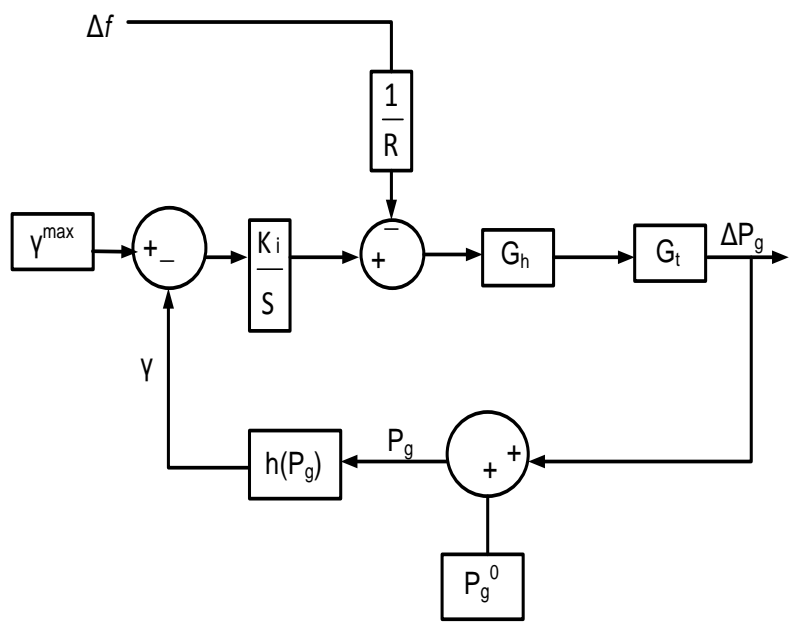

Figure 4. Price based Control for Fully loaded Generator [82]

Automatic generation control scheme suitable for Indian electricity scenario based on the price based frequency dispatch guidelines issued by CERC have been reported in [82]. According to frequency dispatch guidelines issued by CERC, the threshold frequency for each 
generator is one at which the UI price equals to the maximum marginal cost of generation of that particular generator. For above and below threshold frequency, operational guidelines to response to load change for each generator, are different. In first scheme (Figure.4) a price based control for fully loaded generator can be built by comparing the current marginal cost of unit $\gamma$ to its maximum marginal cost $\gamma^{\max }$ and feeding their difference as Generation Control Error (GCE). As the marginal cost of unit changes in response to increase or decrease of generation, the effect of this control is to bring marginal cost back to $\gamma^{\max }$, which corresponds to a generation set point of $100 \%$.

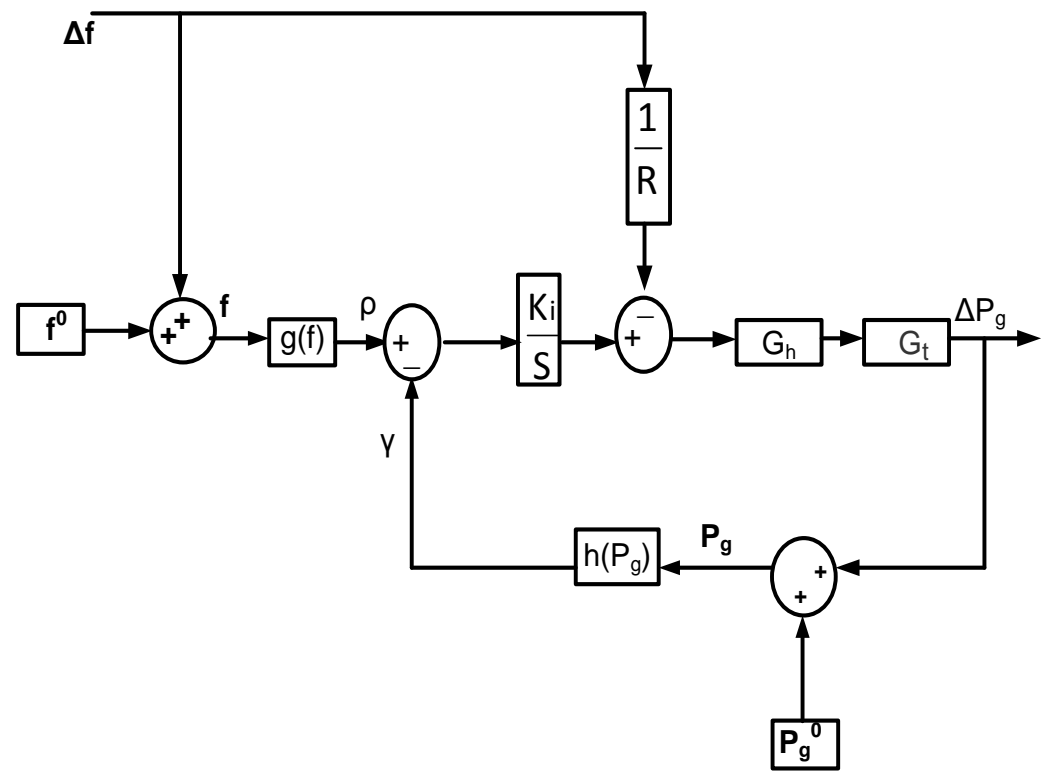

Figure 5. Price based control for partly loaded generator [82]

In second scheme (Figure 5), for the partly loaded units a price based control GCE is the difference between UI price and the marginal cost $\gamma$. With this control, the generator would back down in event of frequency rise above its threshold frequency. The backing down will occur, until the marginal cost of generation unit becomes equal to the UI price, ensuring merit order dispatch.

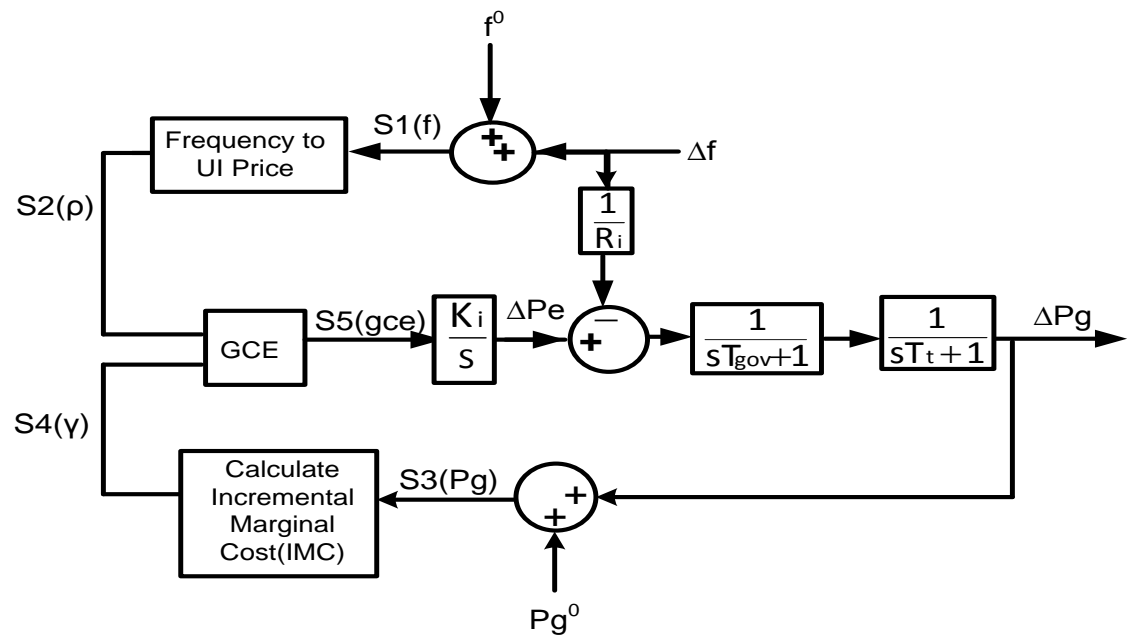

Figure 6. ABT based frequency control loop with modified GCE algorithm [83] 
Modifications to rectify the shortcomings of the proposed model discussed in [80] have been reported in [83]. A new algorithm has been developed to compute Generation Control Error (GCE). A new strategy as shown in (Figure.6) demonstrates that no action is taken by generators if the entire load and other generators stick to their respective schedules, which may reduce unnecessarily UI, among generators. In Ref. [84], authors have proposed a scheme, which integrates use of wind energy through UI based secondary control to improve the transient response. Last but not the least recently in Ref. [85] PSO based optimized price based frequency control scheme for multi-unit power system has been proposed.

\section{Conclusions}

Load frequency control is one of the most profitable ancillary services in deregulated electricity market. This paper has presented an overview on the prevailing frequency regulation service, in India and around the world after the deregulation of electricity market. Article concludes that there is no common rule for frequency regulation service. It varies country to country based on the market structure implemented. Different load frequency control strategies in competitive electricity market with recent research have been briefly reviewed. Real time price based frequency linked LFC schemes in deregulated market have also been described. It has been also observed that little research have been carried out in the area of price based frequency link dispatch scheme. This study intends to be a useful reference and search tool in this area for the aspirant researchers.

\section{References}

[1]. J. Zhong, "On Some Aspects of Design of Electric Power Ancillary Service Markets," Ph.D. Thesis, Chalmers University of Technology, Sweden, 2003.

[2]. Y.G. Rebours, D. S. Kirschen, M. Trotignon, and S. Rossignol, "A Survey of Frequency and Voltage Control Ancillary Services: Technical Features Part I \&II," IEEE Trans. on Power Systems, Vol. 22, No.1, pp. 350-366, February 2007.

[3]. V. Pandurangan, H. Zareipour, and O. Malik, "Frequency Regulation Services, A Comparative Study of Select North American and European Reserve Market," Proc. of North American Power Symposium, pp.1-8, September 2012.

[4]. R. Raineri, S. Rios, and D. Schiele, "Technical and Economic Aspects of Ancillary Services Markets in Electric Power Industry: An international Comparison," Energy Policy, Vol.34, No.13, pp. 1540-1555, September 2006.

[5]. S.K. Parida, S.N. Singh, and S.C. Srivastava, "An Integrated Approach for Optimal Frequency Regulation Service Procurement in India," Energy Policy, Vol. 37, No.8, pp.3020-3034, August 2009.

[6]. Ancillary Services in Indian Context: An Approach Paper, POSOCO. In/uploads/, New Delhi, India, June 2010.

[7]. S.K. Parida, S.N. Singh, S.C. Srivastava, P. Chanda, and A.K. Shukla, "Pros and Cons of Existing Frequency Regulation Mechanism in Indian Power Industry," Proc. of Joint Int. Conf. on Power System Technology and IEEE Power India Conf., pp.1-6, October 2008.

[8]. Unscheduled Interchange Charges and Related Matters Regulation, www.cercind.gov.in,No. L-1(1)/2011-CERC, New Delhi, India, March 2012.

[9]. Deviation Settlement Mechanism and Related Matters Regulations, www.cercind.gov.in .No.L-1/132/2013/CERC, New Delhi, India, January 2014.

[10]. Central Electricity Regulatory Commission. Indian Electricity Grid Code, www.cercind.gov.in, No. L-1/18/2010-CERC, New Delhi, India, April 2010.

[11]. Central Electricity Regulatory Commission, Indian Electricity Grid Code, www.cercind. Gov. in, No. L-1/18/2010-CERC, New Delhi, India, August 2013.

[12]. S.K. Parida, S.N. Singh, and S.C. Srivastava, "Ancillary Services Management Policies in India: An Overview and Key Issue," The Electricity Journal, Vol.22, No.1, pp. 88-97, February 2009. 
[13]. S.K. Parida, S.N. Singh, and S.C. Srivastava, "An Approach to Promote Frequency Regulation Service in India," Int. Journal of Energy Sector Management, Vol. 4, No.1, pp. 6-23, 2010.

[14]. Introduction to Ancillary Services in Indian Electricity Market: A Staff Paper, www.cercind.gov.in, No.18/1/2013-Reg.Aff /CERC. New Delhi, India, April 2013.

[15]. S.K. Soonee, V. Mittal, A. Jain, A. Mani, S.S. Barpanda, M.K. Agarwal, and S.C. Saxena, "Power Exchange Implementation in India and Congestion Management in Multi Exchange Scenario," Posoco. in/ papers/Power\% 20Exchange_Final_22_Jan_09.pdf, National Load Dispatch Center (NLDC), Power Grid Corporation of India Ltd., New Delhi, India, 2009.

[16]. N. Bekhouche, "Automatic Generation Control Before After Deregulation," Proc. of $34^{\text {th }}$ Southeastern Symposium on System Theory, pp. 321-323, March 2002.

[17]. B.H. Bakken, and O.S. Grande, "Automatic generation control in a deregulated power system," IEEE Trans. on Power Systems, Vol.13, No.4, pp. 1401-1406, November 1998.

[18]. H. Bevrani, A. Rezazadeh, and M. Teshnehlab, "Comparison of Existing LFC Approaches in Deregulated Environment," Proc. of $5^{\text {th }}$ Int. Conf. on Power System Management and Control, pp. 238-243, 2002.

[19]. E. Rakhshani, and J. Sadeh, "Practical Viewpoints on Load Frequency Control Problem in a Deregulated Power System," Energy Conversion and Management, Vol.51, No.6, pp.1148-1156, June 2010.

[20]. R.D. Christie, and A. Bose, "Load Frequency Control Issues in Power System Operations After Deregulation," IEEE Trans. on Power Systems, Vol.11, No.3, pp.1191-1200, August 1996.

[21]. J. Kumar, K.H. Ng, and G. Sheble, "AGC Simulator for Price-Based Operation Part -I: A Model," IEEE Trans. on Power Systems, Vol.12, No.2, pp.527-532, May 1997.

[22]. J. Kumar, K.H. Ng, and G. Sheble, "AGC Simulator for Price Based Operation Part-II: Case Study Results," IEEE Trans. on Power Systems, Vol.12, No.2, pp.533-538, May 1997.

[23]. V. Donde, M. A. Pai, and A.I. Hiskens, "Simulation and optimization in an AGC system after deregulation," IEEE Trans. on Power Systems, Vol.16, No.3, pp.481-489, August 2001.

[24]. E. Nobile, and A. Bose, and K. Tomsovic, "Bilateral Market for Load Following Ancillary Services," Proc. of IEEE Power Engineering Society Summer Meeting, Vol.2, pp. 704-706, July 2000.

[25]. E. Nobile, and A. Bose, and K. Tomsovic,“ Feasibility of a Bilateral Market for Load Following," IEEE Trans. on Power Systems, Vol.16, No. 4, pp. 782-787, November 2001.

[26]. E. Tuglie, and F. Torelli, "Load Following Control Schemes for Deregulated Energy Markets," IEEE Trans. on Power Systems, Vol.21, No. 4, pp.1691- 1698, November 2006.

[27]. R. J. Abraham, D. Das, and A. Patra, "Load Following in a Bilateral Market with Local Controllers," Int. Journal of Electrical Power and Energy Systems, Vol. 33, No.10, pp.1648-1657, December 2011.

[28]. D. Rerkpreedapong, and A. Feliache, "Decentralized Load Frequency Control for Load Following Services," Proc. of IEEE Power Engineering Society Winter Meeting, Vol.2, pp. 1252-1257, January 2002.

[29]. K. Sedghisigarchi, A. Feliache, and A. Davari, "Decentralized Load Frequency Control in a Deregulated Environment using Disturbance Accommodation Control Theory," Proc. of $34^{\text {th }}$ Southeastern Symposium on System Theory, pp. 302-306, March 2002.

[30]. B. Tyagi, and S.C. Srivastava, "A Decentralized Automatic Generation Control Scheme for Competitive Electricity Markets," IEEE Trans. on Power Systems, Vol.21, No.1, pp. 312-320, February 2006. 
[31]. W. Tan, H. Zhang, and M. Yu, "Decentralized Load Frequency Control in Deregulated Environments," Int. Journal of Electrical Power and Energy Systems, Vol. 41, No.1, pp.16-26, October 2012.

[32]. A. Morattab, Q. Shafiee, and H. Bevrani, "Decentralized Model Predictive Load Frequency Control for Deregulated Power Systems in a Tough Situation," Proc. of IEEE Conf. on Power Tech., pp.1-5, June 2011.

[33]. S.K. Pandey, N. Kishor, and S. R. Mohanty, "A Novel Decentralized Robust MIMO -PID Load Frequency Controller via Iterative LMI Approach in Deregulated Environment," Proc. of IEEE Students Conf. on Engineering and System, pp.1- 6, April 2013.

[34]. H. Bevrani, Y. Mitani, and K. Tsuji, "Robust Decentralized AGC in a Restructured Power System," Energy Conversion and Management, Vol. 45, No. 15-16, pp.2297-2312, September 2004.

[35]. H. Shayeghi, and H.A. Shayanfar, "Decentralized Robust Load Frequency Control Using Linear Matrix Inequalities in a Deregulated Multi-Area Power System," Journal of Power Engineering Problems, Vol.2, pp.30-38, 2005.

[36]. H. Bevrani,Y. Mitani, and K.Tsuji "Bilateral Based Robust Load Frequency Control", Energy Conversion and Management, Vol. 46, No.7-8, pp. 1129-1146, May 2005.

[37]. H. Shayeghi, and H.A. Shayanfar, "Design of Decentralized Robust LFC in a Competitive Electricity Environment," Journal of Electrical Engineering, Vol. 56, No. 9-10, pp.225236, 2005.

[38]. H. Shayeghi, and H.A. Shayanfar, "Robust Decentralized LFC Design in a Restructured Power System," Int. Journal of Emerging Electrical Power System, Vol. 6, No. 2, August 2006.

[39]. H. Shayeghi, “A Robust Decentralized Power System Load Frequency Control,” Journal of Electrical Engineering, Vol.59, No.6, pp.281-293, 2008.

[40]. H. Shayeghi, and H.A. Shayanfar, "Decentralized Robust AGC Based on Structured Singular Values," Journal of Electrical Engineering, Vol. 57, No.6, pp.305-317, 2006.

[41]. J. Rezvantalab, M.H. Kazemi, and A.K Seddigh, "Multi Area Robust Decentralized Load Frequency Controller Design in a Restructured Power System using Quantitative Feedback Theory," Proc. of IEEE Int. Conf. On Electric Power and Energy Conversion Systems, pp. 1-6, November 2009.

[42]. B. Tyagi, and S.C. Srivastava, "A Fuzzy Logic Based Load Frequency Controller in a Competitive Electricity Environment," Proc. of IEEE Power Engineering Society General Meeting, Vol.2, pp. 560-565, July 2003.

[43]. H. Shayeghi, H. A. Shayanfar, and A. Jalili, "Multi Stage Fuzzy PID Power System Automatic Generation Controller in Deregulated Environments," Energy Conversion and Management, Vol. 47, No.18-19, pp.2829-2845, November 2006.

[44]. H. Shayeghi, H. A. Shayanfar, and A. Jalili, "Multi Stage Fuzzy PID Load Frequency Controller in a Restructured Power System," Journal of Electrical Engineering, Vol.58, No. 2, pp.61-70, 2007.

[45]. H. Shayeghi, H. A. Shayanfar, and A. Jalili, "Robust modified GA based multi stage fuzzy LFC," Energy Conversion and Management, Vol. 48, No. 5, pp.1656 -1670, May 2007.

[46]. A.P. Fathima, and M. A. Khan, "Design of a New Market Structure and Robust Controller for The Frequency Regulation Services in the deregulated power system.," Electric Power Components and Systems, Vol. 36,No. 8, pp. 864-883, June 2008.

[47]. C.S. Rao, S.S. Nagaraju, and P.S. Raju, "Automatic Generation Control of TCPS Based Hydrothermal System under Open Scenario: A Fuzzy Logic Approach," Int. Journal of Electrical Power and Energy System, Vol.31, No.7-8, pp.315-322, September 2009.

[48]. P. G. Rana, R. Umrao, and D.K. Chaturvedi, "Automatic Generation Control with Polar Fuzzy Controller Considering Generation Rate Constraint in Deregulated Power System," Proc. of Int. Conf. on Advances in Engineering, Science and Management, pp. 610 - 615, March 2012. 
[49]. Y.P. Verma, and A. Kumar, "Load Frequency Control in Deregulated Power System With Wind Integrated System Using Fuzzy Controller," Frontiers in Energy, Vol. 7, No. 2, pp. 245-254, June 2013.

[50]. H.A. Shayanfar, and H. Shayeghi, "Decentralized load frequency control of a deregulated electric power system using ANN technique," WSEAS Trans Circuits System, Vol. 4, No.1, pp.38-47, 2005.

[51]. H.A. Shayanfar, and H. Shayeghi, and O.P. Malik, "Robust Decentralized Neural Networks Based LFC in a Deregulated Power System," Electric Power Systems Research, Vol.47, No.3-4, pp. 241-251, March 2007.

[52]. H. Bevrani, T. Hiyama, Y. Mitani, K. Tsuji,and M. Teshnehlab, "Load Frequency Regulation Under a Bilateral LFC Scheme Using Flexible Neural Networks," Engineering Intelligent Systems, Vol. 14, No.2, pp. 109-117, June 2006.

[53]. N. P. Padhy, and B. Tyagi, "Artificial Neural Network Based Multi Area Automatic Generation Control Scheme for A Competitive Electricity Market Environment," Proc. of Int. Conf. on Power Systems, pp.1- 6, December 2009.

[54]. S.H. Hosseini, and E.H. Etemadi, "Adaptive Neuro-Fuzzy Inference System Based Automatic Generation Control," Electric Power Systems Research, Vol.78, No.7, pp. 1230-1239, July 2008.

[55]. C.S. Rao, "Adaptive Neuro Fuzzy Based Load Frequency Control of Multi Area System Under Open Market Scenario," Proc. of Int. Conf. on Advances in Engineering, Science and Management, pp. 5-10, March 2012.

[56]. H. Shayeghi, H.A. Shayanfar, and A. Jalili, "LFC Design of A Deregulated Power System With TCPS using PSO," World Academy of Science, Engineering and Technology, Vol. 28, pp. 670-678, 2009.

[57]. P. Bhatt, R. Roy, and S.P. Ghoshal, "Optimized Multi Area AGC Simulation in Restructured Power Systems," Electrical Power and Energy Systems, Vol.32, No.4, pp.311-322, May 2010.

[58]. A. Demiroren, and H.L. Zeynelgil, "GA Application to Optimization of AGC in ThreeArea Power System After Deregulation," Int. Journal of Electrical Power and Energy Systems, Vol. 29, No.3, pp. 230-240, March 2007.

[59]. S. Bhongade, B. Tyagi, and H.O. Gupta, "Genetic Algorithm Based PID Controller for Frequency Regulation Ancillary Services," Int. Journal of Engineering Science and Technology, Vol. 2, No.12, pp. 6902-6908, 2010.

[60]. G. Hou, X. Zheng, L. Qin, and J. Zhang, "Application of GA for Three-Area Power System After Deregulation with Valve Position Limit," Proc. of IEEE Conf. on Control and Decision, pp.1018 -1022, May 2012.

[61]. R.Roy, S.P.Ghoshal, and P. Bhatt, "Evolutionary Computation Base Four Area Automatic Generation Control in Restructured Environment," Proc. of Int. Conf. on Power system, pp. 1-6, 2009.

[62]. K. Wadhwa, J. Raja, and S.K. Gupta, "BF Based Integral Controller for AGC of Multi Area Thermal System under Deregulated Environment," Proc. of IEEE Conf. on Power India, pp. 1- 6, December 2012.

[63]. J. Javidan, and A. Ghasemi, "A Novel Fuzzy RPID Controller for Multi Area AGC With IABC Optimization," Journal of Electrical Engineering, Vol. 13, 2013.

[64]. H. Shayeghi, A. Jalili, and H.A. Shayanfar, "A Robust Mixed H2/H$\infty$ based LFC of a Deregulated Power System Including SMES," Energy Conversion and Management, Vol.49, No.10, pp. 2656-2668, October 2008.

[65]. P. Bhatt, R. Roy, and S.P. Ghoshal, "Coordinated Control of SSSC and SMES in Competitive Electricity Market for Load Frequency Control," Proc. of IEEE $11^{\text {th }}$ Int. Conf. on Probabilistic Methods Applied to Power Systems, pp. 42- 47, June 2010.

[66]. P. Bhatt, R. Roy, and S.P. Ghoshal, "Load Frequency Control of Interconnected Restructured Power System Along with DFIG and Coordinated Operation of TCPS- 
SMES," Proc. of IEEE $11^{\text {th }}$ Int. Conf. on Probabilistic Methods Applied to Power Systems (PMAPS ), pp. 131-136, June 2010.

[67]. A. J. Raja and R. Christoberasir. "New robust energy storage devices for deregulated AGC problem," Global Journal of Researches in Engineering Electrical and Electronics Engineering, Vol.13, No. 2, pp. 37-54, 2013.

[68]. A. J. Raja and R. Christoberasir, "Frequency Excursion of Three Area H-T-H Deregulated System Optimized by BF Algorithm with Energy Storage Devices," Journal of Electrical Engineering, Vol. 14, No.2, pp.1-9, June 2014.

[69]. D. Menniti, A. Pinnarelli, and N. Scordino, " Using a FACTS Device Controlled by a Decentralized Control Law to Damp the Transient Frequency Deviation in a Deregulated Electric Power System,” Electric Power Systems Research, Vol.72, No.3, pp.289-298, 2004.

[70]. T.A. Kumar, V.S. Krishna, and N.V. Ramana, "Improvement of Dynamic Performance of Three Area Thermal System Under Deregulated Environment using AC Tie Line Parallel with HVDC link," Proc. of IEEE Int. Conf. on Power and Energy Systems, pp.1-6, December 2011.

[71]. L. Shanmukharao, and N.V. Ramada, "LFC Scheme for Multi Area Deregulated Power System Connected with HVDC link," Proc. of IEEE Int. Conf. on Power Electronics, Drives and Energy Systems, pp.1- 6, Dec., 2012.

[72]. H. Shayeghi, H.A. Shayanfar, and A. Jalili, "Load Frequency Control Strategies: A state of the Art Survey for The Researcher," Energy Conversion and Management, Vol. 50, No.2, pp. 344-353, Feb, 2009.

[73]. S. Pandey, S.R. Mohanty, and N. Kishor, "A Literature Survey on Load Frequency Control for Conventional and Distribution Generation Power Systems," Renewable and Sustainable Energy Reviews, Vol. 25, pp. 318-334, September 2013.

[74]. A.W. Berger, and P.C. Schweppe, "Real Time Pricing to Assist in Load Frequency Control," IEEE Trans. on Power Systems, Vol. 4, No.3, pp.920-926, August 1989.

[75]. K. Bhattacharya, D. Chattopadhyay, and J. Parikh, "Real Time Adaptive Pricing for Load Frequency Control in An Interconnected Power System," Int. Journal of Power and Energy Systems, Vol.18, pp. 102- 109, 1998.

[76]. K. Bhattacharya, "Frequency Based Pricing As an Alternative to Frequency Regulation Ancillary Service," Proc. of $11^{\text {th }}$ National Power System Conf., pp. 210-215, December 2010.

[77]. J. Zhong, and K. Bhattacharya, "Frequency Linked Pricing As an Instrument for Frequency Regulation in Deregulated Electricity Markets," Proc. of IEEE Power Engineering Society Summer Meeting, pp. 66-571, July 2003.

[78]. H. Zhao, and K. Bhattacharya, "Design of Frequency Regulation Service Market Based on Price and Demand Elasticity Bids," Proc. of Power Systems Computation Conf., Liege, Belgium, August 2005.

[79]. K.V.V. Reddy, A. Kumar, and S. Chanana, "Frequency Linked Pricing As an Instrument for Frequency Regulation Market and ABT Mechanism," Proc. of IEEE Int. Conf. on Power Electronics, Drives and Energy System, pp. 1-7, December 2006.

[80]. Tyagi, B., and Srivastava, S.C. "A Mathematical Framework for Frequency Linked Availability Based Tariff Mechanism in India," Proc. of $13^{\text {th }}$ National Power Systems Conf., pp. 516-521, December 2004.

[81]. S. Chanana, and A. Kumar, "Proposal for a Real-Time Market Based on Indian Experience of Frequency Linked Prices," Proc. of IEEE Conf. on Global Sustainable Energy Infrastructure, pp.17-18, November 2008.

[82]. S. Chanana, "Some Important Aspects of Price Based Frequency Regulation and Pricing in Competitive Market", PhD. Thesis, National Institute of Technology Kurukshetra, India, April 2011. 
[83]. S. Chanana, and A. Kumar, "A Price Based Automatic Generation Control Using Unscheduled Interchange Price Signals in Indian Electricity System," Int. Journal of Engineering, Science and Technology, Vol.2, No. 2, pp. 23-30, 2010.

[84]. Y.P. Verma, and A. Kumar, "Participation of Doubly Fed Induction Generator Based Wind Turbine in Frequency Regulation with Frequency-Linked Pricing," Electric Power Components and Systems, Vol. 40, No.14, pp.1586-1604, October 2012.

[85]. S. M. Pujara, and C.D. Kotwal, "Optimized Integral Gain Controllers for Price Based Frequency Regulation of Single Area Multi-Unit Power System," Int. Journal on Electrical Engineering and Informatics, Vol.6, No. 2, pp.306-323, June 2014.

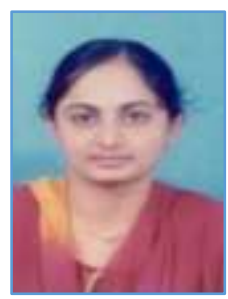

Shital M. Pujara received her M.E. degree from S. P. University of V. V. Nagar, Anand, Gujarat, India. She has been a faculty member of Electrical Engineering Dept. in Sardar Vallabhbhai Patel Institute of Technology, Vasad, Gujarat, India since1997. At present she is pursuing her Ph.D. from CITC, Changa, Gujarat, India. Her areas of interests are in Restructured Power System, power System Economics, Simulation Techniques, and Evolutionary Algorithms. Email: smpujara4@yahoo.co.in, M- 9825707091.

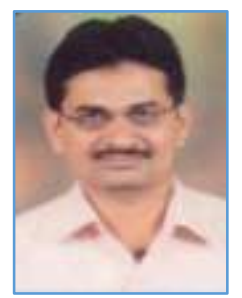

Chetan D. Kotwal is a Professor at Department of Electrical Engineering, SVIT, Vasad, Gujarat, India. He received his B.E. and M.E. degrees from M.S. University of Baroda, Vadodara. He obtained his PhD. from Indian Institute of technology, Roorkee, India. His research interests are in Power Electronics applications to Power System, FACTS controllers and Power System Dynamics, Smart Grid, Power System Economics, Swarm Intelligence. Email: chetan.kotwal@ gmail.com, M - 9909006055 